Article

\title{
Adsorption and Desorption Properties of Total Flavonoids from Oil Palm (Elaeis guineensis Jacq.) Mature Leaf on Macroporous Adsorption Resins
}

\author{
Mohamad Shazeli Che Zain ${ }^{1}$, Soo Yee Lee ${ }^{1}$, Chian Ying Teo ${ }^{2, *}$ and Khozirah Shaari ${ }^{1, *(1)}$ \\ 1 Laboratory of Natural Products, Institute of Bioscience, Universiti Putra Malaysia, 43400 Serdang, Selangor, \\ Malaysia; shazelizain@gmail.com (M.S.C.Z.); daphne.leesooyee@gmail.com (S.Y.L.) \\ 2 Department of Pharmaceutical Chemistry, School of Pharmacy, International Medical University, 57000 \\ Kuala Lumpur, Malaysia \\ * Correspondence: TeoChianYing@imu.edu.my (C.Y.T.); khozirah@yahoo.com.my (K.S.); \\ Tel.: +60-3-27317742 (C.Y.T.); +60-3-8942148 (K.S.)
}

Academic Editors: Celestino Santos-Buelga and Ana M. González-Paramás

Received: 1 December 2019; Accepted: 8 January 2020; Published: 11 February 2020

check for updates

\begin{abstract}
Three different macroporous resins (XAD7HP, DAX-8, and XAD4) were evaluated for their adsorption and desorption properties in preparing flavonoid-enriched oil palm (Elaeis guineensis Jacq.) leaf extract. The influences of initial concentration, solution $\mathrm{pH}$, contact time, and desorption solvent (ethanol) concentration were determined by static sorption/desorption methods. The optimal condition for adsorption of flavonoids was achieved when the solution of the extract was adjusted to $\mathrm{pH} 7$, reaching equilibrium after $1440 \mathrm{~min}$ at $298 \mathrm{~K}$. The adsorption process was well described by a pseudo-second-order kinetics model, while the adsorption isotherm data fitted well with a Freundlich model. The adsorption by each resin was via an exothermic and physical adsorption process. Based on the static experiment results, XAD7HP was found to be the most appropriate adsorbent, while $80 \%$ ethanol was the best solvent for desorbent. Further evaluation of its dynamic adsorption and desorption characteristics on a packed glass column showed that XAD7HP could enrich the OPL total flavonoid content by a 3.57-fold increment. Moreover, UHPLC-UV/PDA and UHPLC-MS/MS analysis revealed that apigenin and luteolin derivatives were selectively adsorbed by XAD7HP. Additionally, both the crude OPL extract and the flavonoid-enriched fraction have good DPPH and NO free radical scavenging activities. Multiple interactions between the flavonoids and cross-linked polymeric XAD7HP resin through van der Waals forces and hydrogen bonding described the sorption processes. Therefore, by utilizing this method, the flavonoid-enriched fraction from crude OPL extract could be used as a potential bioactive ingredient in nutraceutical and pharmaceutical applications at minimum cost with optimum efficiency.
\end{abstract}

Keywords: oil palm (Elaeis guineensis Jacq.) leaf; total flavonoids; macroporous resins; adsorption; desorption; antioxidant activity

\section{Introduction}

The genus Elaeis belongs to the palm family (Arecaceae) which is one of the key members of the allogamous arborescent monocot group under the order Arecales [1]. Elaeis guineensis Jacq. is believed to have originated in West Africa [2]. Presently, it is a major commodity crop of some countries in Southeast Asia, notably Indonesia and Malaysia [3]. Oil palm cultivation produces a huge amount of waste material in the form of oil palm trunks, fronds, and leaves. These waste materials, especially oil palm leaves (OPL), contain phytochemicals that could be useful for various applications such as medicines for treating wounds, cancer, and cardiovascular and kidney diseases [4]. OPL extract was 
shown to be safe for use in disease treatments based on the absence of adverse effects in several studies on rodents [5,6].

Previous chemical investigations revealed that OPL extract is rich in flavonoids, mainly flavonoid O-glycosides and flavonoid C-glycosides [7]. As a class of compounds, flavonoids are well known to have positive effects on human health with reports of being hepatoprotective, antioxidative, and antidiabetic, among others [8]. Presently, there is a high demand for flavonoids globally by the nutraceutical and pharmaceutical industries, which is forecasted to reach approximately RM 4.40 billion by the year 2025 [9]. Thus, to meet requirements, the availability of simple and efficient methods for their separation and purification is needed.

Conventionally, flavonoids are separated from plant matrixes by methods that require high amounts of solvents, long separation time and low recovery. These methods include solid-liquid extraction, liquid-liquid extraction, and column chromatography, either packed with silica gel or Sephadex LH-20. Macroporous resin (MAR), with the property of high cross-linkage and many permanent pores, was also utilized in the separation and purification of flavonoids, for example, separation of flavonoids from Lycium barbarum L. [10], Populus tomentosa Carr. [11], Oleo europaea L. [12], Glycyrrhiza glabra L. [13], Eriobotrya japonica (Thunb1.) Lindl. (Loquat) [14], and Hippophae rhamnoides L. (Sea buckthorn) [15], among others. The superiority of MARs in separating flavonoids from plant extracts is said to be due to the special characteristics of flavonoids themselves as they have benzene rings and several hydrogen groups attached to their aglycone, helping the appropriate MAR, with proper average pore diameter, polarity, and surface area, to adsorb these compounds. Previous researches showed that such properties significantly contribute to the sorption capacity of MARs $[13,16,17]$. Therefore, MARs are a suitable medium in devising a simple and effective method for the separation and purification of flavonoids from plant extracts. In the present study, three MARs with different properties (XAD4, XAD7HP, and DAX-8) were evaluated for their adsorption and desorption characteristics, thermodynamics, and kinetics, in the static sorption of total flavonoids from OPL extract. The resin with the best static sorption characteristics was further assessed for purification efficiency based on its dynamic adsorption and desorption characteristics on a packed glass column.

\section{Results and Discussion}

\subsection{Adsorption Kinetics of OPL Total Flavonoids on Selected MARs}

The adsorption kinetics of the MARs for total flavonoids in the OPL extract was firstly investigated in order to determine the equilibrium contact time and optimal $\mathrm{pH}$ solution. The solution initial $\mathrm{pH}$ value affects the affinity of the flavonoids to the MAR [11]. Hence, in the adsorption kinetics experiment, three $\mathrm{pH}$ values $(5,7$, and 9) were evaluated. The adsorption curves obtained from the experiments are shown in Figure 1. For the three selected MARs, the adsorption capacity, $q_{t}(\mathrm{mg} / \mathrm{g}$ dry MAR), increased with increasing contact time $t$, reaching equilibrium within 1440 min. For all the resins, $\mathrm{pH} 7$ showed the highest $q_{t}$ values in comparison to $\mathrm{pH} 5$ and $\mathrm{pH} 9$. This indicated that the adsorption of the OPL total flavonoids on the selected resins was more favorable in neutral conditions than in acidic and basic conditions. This could be due to hydrogen-bonding interactions being reduced at higher $\mathrm{pH}$ value. Hydroxyl groups attached to the aglycone were hydrolyzed into hydrogen ions, resulting in low adsorption capacity [18]. Based on the result, the OPL extract solution was adjusted to pH 7 in subsequent experiments. 
A

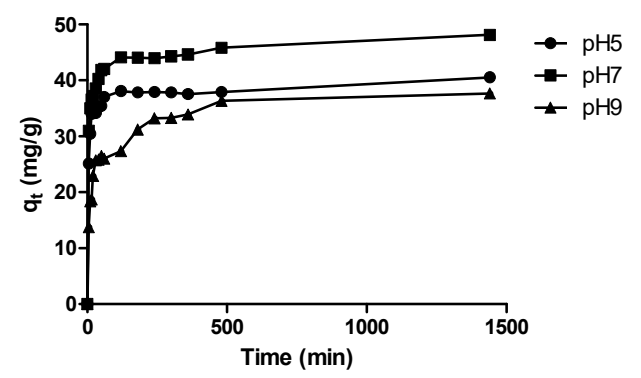

C

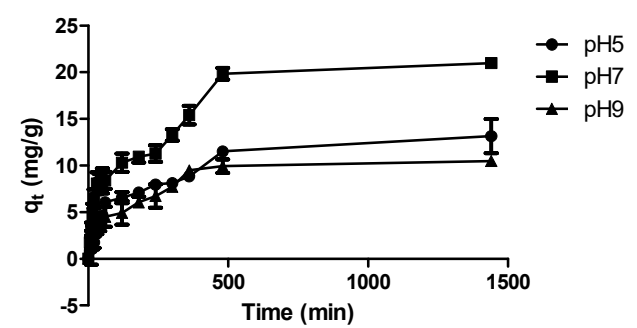

B

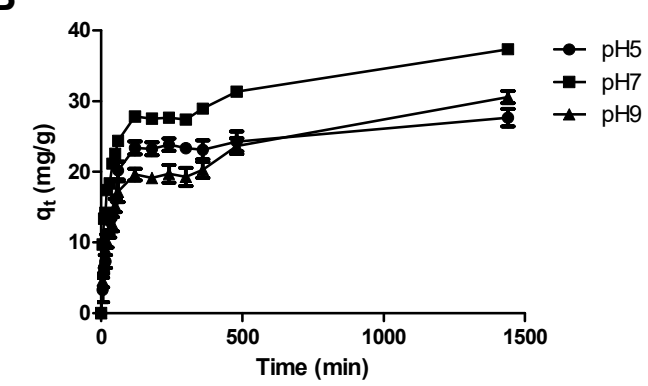

D

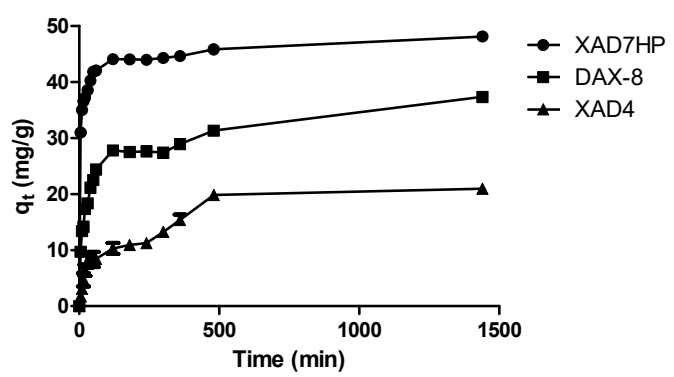

Figure 1. Time curves for adsorption kinetics of the selected MARs for OPL total flavonoids. (A) XAD7HP, (B) DAX-8, and (C) XAD4 at different $\mathrm{pH}$; (D) comparison of the time curves for the different MARs at $\mathrm{pH} 7$.

The pseudo-first-order, pseudo-second-order, and particle diffusion kinetics models were analyzed to elucidate the adsorption behaviors and mechanism of the selected MARs. The derived parameters such as correlation coefficient and dynamic parameters are summarized in Table 1 . The pseudo-second-order kinetic model was the more favorable model in demonstrating the adsorption processes of OPL total flavonoids on the selected MARs with good correlation $\left(R^{2}\right)$ values in comparison to the pseudo-first-order kinetics model. Similar results were reported by other authors who also investigated the adsorption of total flavonoids present in various plants on different MARs $[10,14,16]$.

Table 1. Pseudo-first-order and pseudo-second-order kinetics equations and related model parameters of OPL total flavonoids on the selected MARs.

\begin{tabular}{|c|c|c|c|c|c|c|c|c|c|c|c|}
\hline \multirow[b]{2}{*}{ Resins } & \multirow[b]{2}{*}{$\mathrm{pH}$} & \multirow{2}{*}{$\begin{array}{c}q_{e} \\
(\exp )(\mathrm{mg} / \mathrm{g})\end{array}$} & \multicolumn{3}{|c|}{ Pseudo-First-Order } & \multicolumn{3}{|c|}{ Pseudo-Second-Order } & \multicolumn{3}{|c|}{ Intraparticle Diffusion } \\
\hline & & & $k_{1}$ & $\begin{array}{l}q_{e}(\mathrm{cal}) \\
(\mathrm{mg} / \mathrm{g})\end{array}$ & $R^{2}$ & $k_{2}$ & $\begin{array}{l}q_{e} \text { (cal) } \\
(\mathrm{mg} / \mathrm{g})\end{array}$ & $R^{2}$ & $C$ & $k_{p}$ & $R^{2}$ \\
\hline \multirow{3}{*}{ XAD7HP } & 5 & 40.5667 & 0.0026 & 6.3726 & 0.5460 & 0.0120 & 38.0228 & 0.9999 & 31.7520 & 0.3707 & 0.6049 \\
\hline & 7 & 48.1583 & 0.0034 & 10.1381 & 0.7732 & 0.0045 & 45.6621 & 0.9996 & 34.8670 & 0.5890 & 0.7467 \\
\hline & 9 & 37.6979 & 0.0050 & 17.4023 & 0.9444 & 0.0016 & 36.2319 & 0.9956 & 17.2340 & 0.9540 & 0.8673 \\
\hline \multirow{3}{*}{ DAX-8 } & 5 & 27.6583 & 0.0041 & 15.1727 & 0.7054 & 0.0014 & 25.7731 & 0.9969 & 6.4897 & 1.0203 & 0.7685 \\
\hline & 7 & 37.3583 & 0.0027 & 19.7707 & 0.7933 & 0.0018 & 30.9598 & 0.9957 & 12.9690 & 0.9407 & 0.8157 \\
\hline & 9 & 30.5958 & 0.0022 & 19.8004 & 0.7973 & 0.0016 & 22.9885 & 0.9886 & 6.9934 & 0.8093 & 0.8353 \\
\hline \multirow{3}{*}{ XAD4 } & 5 & 13.1521 & 0.0034 & 11.3441 & 0.9153 & 0.0009 & 11.9474 & 0.9573 & 0.2973 & 0.4973 & 0.9422 \\
\hline & 7 & 20.9875 & 0.0042 & 17.8553 & 0.8235 & 0.0008 & 18.3824 & 0.9184 & 2.2351 & 0.7137 & 0.9162 \\
\hline & 9 & 10.4937 & 0.0052 & 8.9692 & 0.9312 & 0.0014 & 10.2459 & 0.9400 & 1.0913 & 0.4005 & 0.9677 \\
\hline
\end{tabular}

The $C, k_{p}$, and $R^{2}$ obtained from the intra-particle diffusion curves of the selected MARs are shown in Table 1. The adsorption of flavonoids on XAD4 was governed by the intra-particle diffusion process, as indicated by the good linear trend over time. However, the diffusion curves for XAD7HP and DAX-8 exhibited weak linear trends over time, which indicated that the adsorption of the flavonoids on XAD7HP and DAX-8 may involve multiple processes. There were three stages involved in the 
diffusion, comprising boundary layer diffusion (0-10 or $60 \mathrm{~min}$ ), gradual adsorption (10-120 or 60-1440 $\mathrm{min}$ ), and equilibrium (120-1440 $\mathrm{min}$ ) stages. The first stage was attributed to the immediate utilization of the most readily available adsorbing sites on the resin surfaces, while the second stage involved a gradual diffusion of adsorbate from the surface site into the inner pores. The XAD7HP resin underwent a third stage where the diffusion of flavonoids was at equilibrium. The results revealed that the initial portion of flavonoid adsorption by resins may be governed by the initial intra-particle transport of flavonoids controlled by a surface diffusion process, while the later stage is controlled by pore diffusion. For better visualization, a schematic diagram of the whole adsorption process of OPL total flavonoids on XAD7HP resin is illustrated in Figure 2.

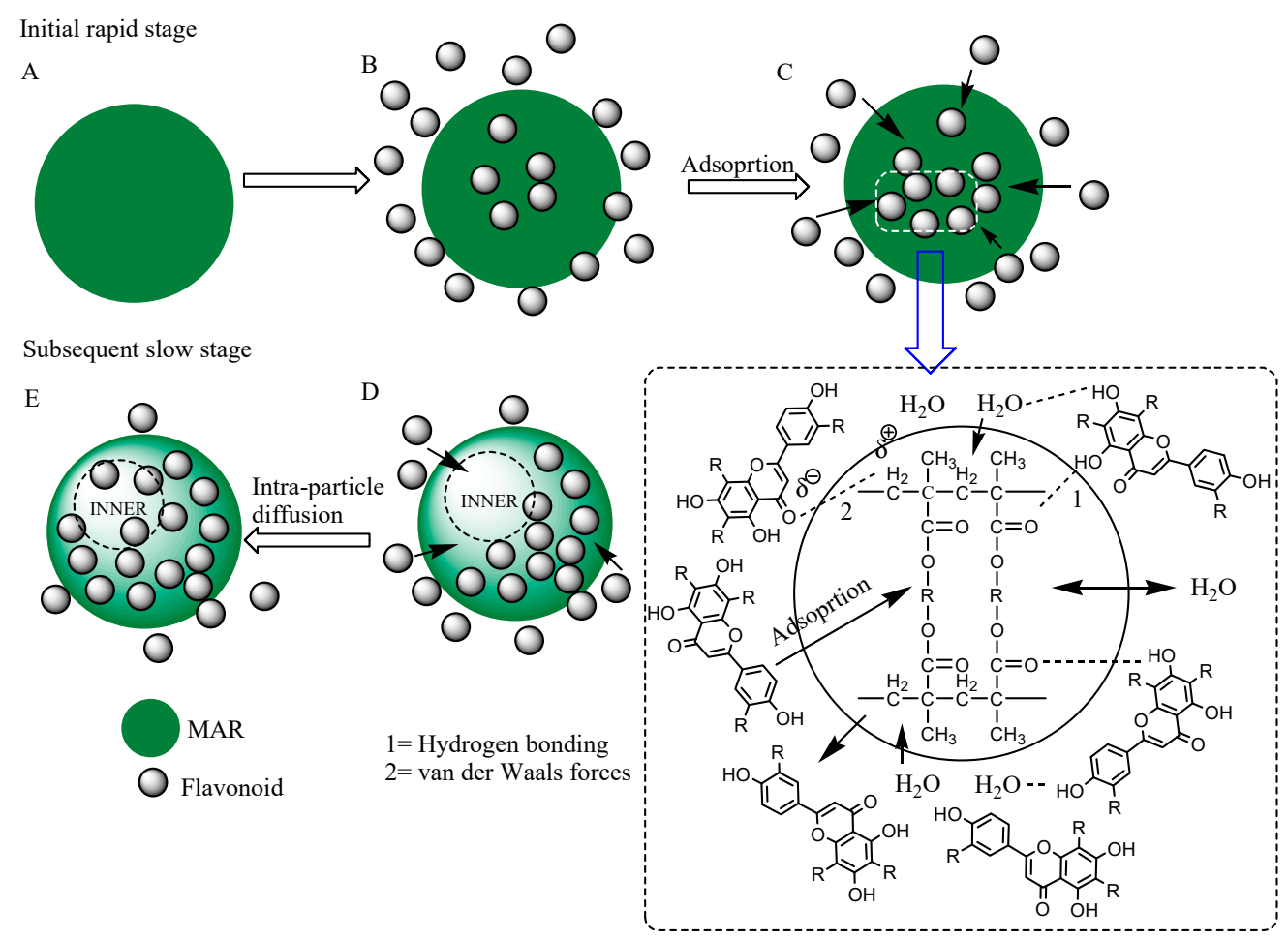

Figure 2. Schematic diagram of the adsorption process of OPL total flavonoids on XAD7HP resin.

Interestingly, for all three resins, the curves did not pass through the origin, which indicated that both boundary layer diffusion and intraparticle diffusion were the rate-controlling factors of the adsorption [14,19]. The particle diffusion kinetics models could not represent the entire adsorption process well because of the weak correlation coefficients [19]. However, it could define a definite mechanism of adsorption at a certain stage.

\subsection{Adsorption Thermodynamics of OPL Total Flavonoids on the Selected MARs}

The equilibrium adsorption isotherms were investigated at $298 \mathrm{~K}, 308 \mathrm{~K}, 318 \mathrm{~K}$, and $328 \mathrm{~K}$ for each of the selected resins. As shown in Figure 3, it was noticeable that lower temperatures were advantageous for the adsorption of flavonoids on the resins. The curves displayed an upward trend with increasing equilibrium concentration of flavonoids for each of the tested temperatures. However, the slope of the $q_{e}$ vs. $C_{e}$ plots declined with an increase in temperature, for all the selected resins. A subsequent investigation was carried out at $298 \mathrm{~K}$ since the optimal adsorption capacity was found to be at this temperature. 
A

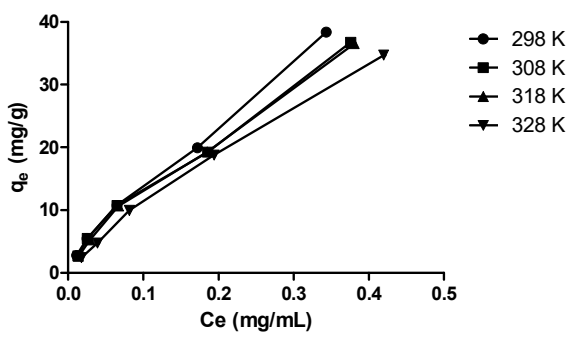

C

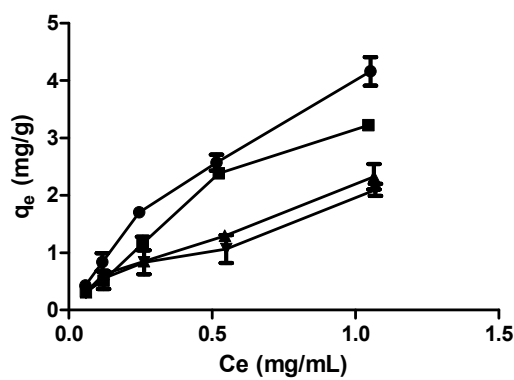

B

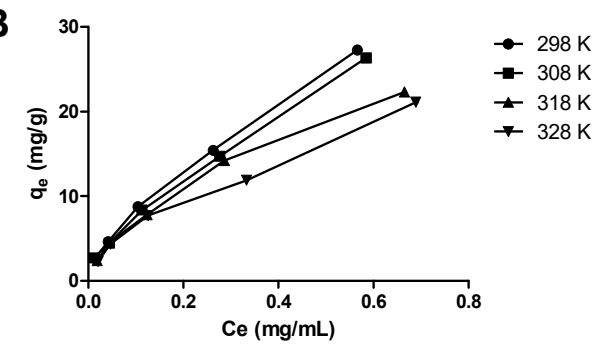

D

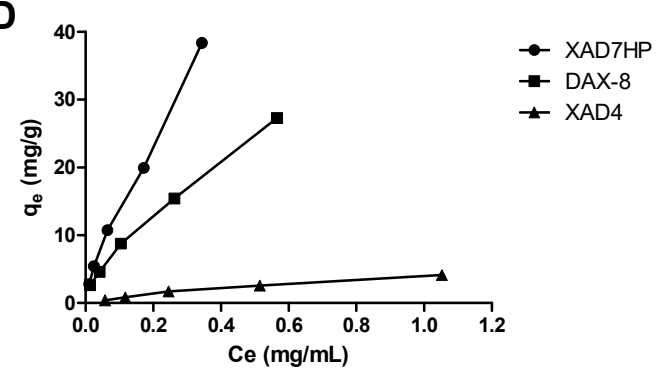

Figure 3. Adsorption isotherms curves of OPL total flavonoids on (A) XAD7HP, (B) DAX-8, and (C) XAD4 at different temperatures; (D) comparison of adsorption isotherms of the selected MARs at $298 \mathrm{~K}$.

The adsorption behavior was further assessed using the Langmuir and Freundlich adsorption isotherm models. After model fitting, the Langmuir model gave mostly weak correlation coefficients $\left(R_{1}^{2}\right)$ and, therefore, was not suitable to explain the adsorption behavior of XAD7HP, DAX-8, and XAD4 at the different temperatures, except for XAD4 at $298 \mathrm{~K}$, XAD7HP at $328 \mathrm{~K}$, and DAX-8 at 318 $\mathrm{K}$ [20]. The Langmuir isotherm model was applied well to many monolayer solid-liquid adsorption processes [21]. The Langmuir constants, $q_{m}$ and $K_{L}$, were calculated from the linear plot $C_{e} / q_{e}$ vs. $C_{e}$ and listed in Table 2. The equilibrium parameter $R_{L}$, a dimensionless constant, is a useful parameter to denote the important characteristics of the Langmuir isotherm [22]. The $R_{L}$ is calculated by the following equation:

$$
R_{L}=\frac{1}{1+K_{L} C_{o}},
$$

where $C_{o}$ is the highest initial concentration of flavonoid $(\mathrm{mg} / \mathrm{mL})$, and $K_{L}$ is the calculated value which indicates the affinity between the absorbent and adsorbate molecules. The $R_{L}$ value gives a sign of the isotherm shape which is either unfavorable $\left(R_{L}>1\right)$, linear $\left(R_{L}=1\right)$, favorable $\left(0<R_{L}<1\right)$, or irreversible $\left(R_{L}=0\right)$ [16]. As shown in Table 2, the values of $R_{L}$ were less than one, so the adsorption of flavonoids onto the MARs was a favorable process.

The Freundlich constants, $K_{f}$ and $1 / n$, were calculated from the $q_{e}$ vs. $C_{e}$ plot. As shown in Table 2, the Freundlich model exhibited good correlation coefficients at different temperatures, which suggested it to be a good model to reflect the adsorption equilibrium of the OPL total flavonoids on the selected MARs. To determine the adsorption intensity or surface heterogeneity, the $1 / n$ value was measured [15]. When the value of $1 / n$ is greater than one, adsorption is said to be difficult to occur [23]. In the present work, the $1 / n$ values were all less than one, which indicated that the adsorption of flavonoids on the selected MARs was favorable. This was in agreement with the results shown by $R_{L}$. Based on the Van't Hoff equation, the enthalpy changes $(\Delta \mathrm{H})$ for XAD4, XAD7HP, and DAX-8 were calculated as $-19.96 \mathrm{~kJ} / \mathrm{mol},-7.49 \mathrm{~kJ} / \mathrm{mol}$, and $-13.41 \mathrm{~kJ} / \mathrm{mol}$, respectively. The negative values of enthalpy changes $(\Delta \mathrm{H})$ for those resins recommended that the adsorption process was exothermic, and low temperature was good for the adsorption process [24]. Meanwhile, the absolute values of enthalpy changes $(\Delta \mathrm{H})$, for the selected MARs, were less than $20 \mathrm{~kJ} / \mathrm{mol}$, demonstrating that the adsorption of the OPL total flavonoids on the resin surface was governed by physisorption rather than chemisorption [25]. 
Table 2. Langmuir model, Freundlich model, and thermodynamic parameters of OPL total flavonoids on the XAD4, XAD7HP, and DAX-8 resins.

\begin{tabular}{|c|c|c|c|c|c|c|c|c|c|}
\hline \multirow{2}{*}{ Resins } & \multirow{2}{*}{$T(\mathrm{~K})$} & \multicolumn{4}{|c|}{ Langmuir Equation } & \multicolumn{3}{|c|}{ Freundlich Equation } & \multirow{2}{*}{$\begin{array}{c}\Delta H \\
(k J / m o l)\end{array}$} \\
\hline & & $q_{m}$ & $K_{L}$ & $R_{L}$ & $R_{1}^{2}$ & $1 / n$ & $K_{f}$ & $R_{2}^{2}$ & \\
\hline \multirow{4}{*}{ XAD4 } & 298 & 4.3497 & 0.4419 & 0.6706 & 0.9401 & 0.6894 & 3.6247 & 0.9351 & \multirow{4}{*}{-19.96} \\
\hline & 308 & 5.0352 & 0.8489 & 0.5146 & 0.8882 & 0.7879 & 3.1212 & 0.9660 & \\
\hline & 318 & 3.6088 & 0.7232 & 0.5544 & 0.8412 & 0.6507 & 2.1153 & 0.9802 & \\
\hline & 328 & 3.0609 & 0.6670 & 0.5743 & 0.7856 & 0.6260 & 1.8461 & 0.9741 & \\
\hline \multirow{4}{*}{ XAD7HP } & 298 & 67.568 & 0.3108 & 0.7433 & 0.8218 & 0.7450 & 80.926 & 0.9967 & \multirow{4}{*}{-7.49} \\
\hline & 308 & 61.350 & 0.3006 & 0.7496 & 0.8561 & 0.7381 & 74.068 & 0.9908 & \\
\hline & 318 & 66.667 & 0.3600 & 0.7143 & 0.8821 & 0.7667 & 76.342 & 0.9943 & \\
\hline & 328 & 86.207 & 0.6466 & 0.5819 & 0.9575 & 0.8429 & 74.790 & 0.9973 & \\
\hline \multirow{4}{*}{ DAX-8 } & 298 & 39.370 & 0.3071 & 0.7456 & 0.8745 & 0.6328 & 37.051 & 0.9960 & \multirow{4}{*}{-13.41} \\
\hline & 308 & 37.594 & 0.3195 & 0.7379 & 0.8269 & 0.5953 & 32.590 & 0.9845 & \\
\hline & 318 & 30.960 & 0.2879 & 0.7576 & 0.9517 & 0.6238 & 29.689 & 0.9970 & \\
\hline & 328 & 27.933 & 0.2961 & 0.7524 & 0.8951 & 0.6045 & 25.578 & 0.9912 & \\
\hline
\end{tabular}

\subsection{Static Desorption of OPL Total Flavonoids from the Selected MARs}

Ethanol is an organic solvent known for several favorable properties, such as it being easily removed from a solution, recyclable, inexpensive, with low toxicity and, therefore, safe for human use $[13,26]$. Thus, it was selected as a desorbent in the present study. As shown in Figure 4, the desorption ratio of flavonoids was directly proportional to the ethanol concentration, meaning that when the desorption ratio increased, the ethanol concentration also increased. After reaching the peak value, the desorption ratio decreased with a further increase in ethanol concentration. The competing interactions between the intermolecular forces of adsorption on the resins and dissolution in the solvent play a significant role in the desorption of flavonoids from the resins. The flavonoids would be desorbed from the resin into the solvent when intermolecular forces are recessive [11]. It was observed that, at $80 \%$ aqueous ethanol, the desorption value was the highest. Hence, a high ethanol concentration $(80 \%)$ was selected in the dynamic desorption study to ensure complete elution. In comparison with DAX-8 and XAD4, XAD7HP showed the best desorption ratio of about $80 \%$ at $80 \%$ ethanol concentration. Thus, XAD7HP was selected as the most suitable resin in the dynamic experiments.

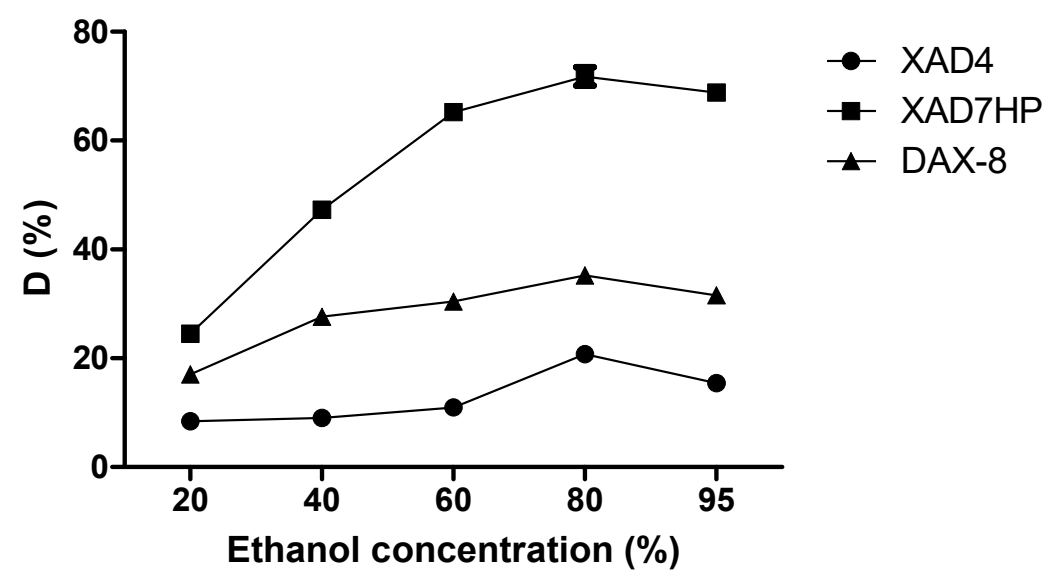

Figure 4. Effect of ethanol concentration on desorption ratio $(D)$ of OPL total flavonoids from the selected MARs. 


\subsection{Dynamic Adsorption and Desorption of OPL Total Flavonoids from XAD7HP}

The dynamic breakthrough curve for XAD7HP was constructed based on the eluting volume and the ratio of the TFC of the eluting volume to the TFC of the original OPL extract $\left(C / C_{0}\right)$. The breakthrough and the saturation points are represented by $5 \%$ and $95 \%$ of the $C / C_{o}$ ratio, respectively. As shown in Figure 5A, the breakthrough and saturation points for OPL total flavonoids on XAD7HP were before $15 \mathrm{~mL}$ and after $80 \mathrm{~mL}$, respectively. It was also observed that, after the breakthrough point, the adsorption increased rapidly up to the saturation point.
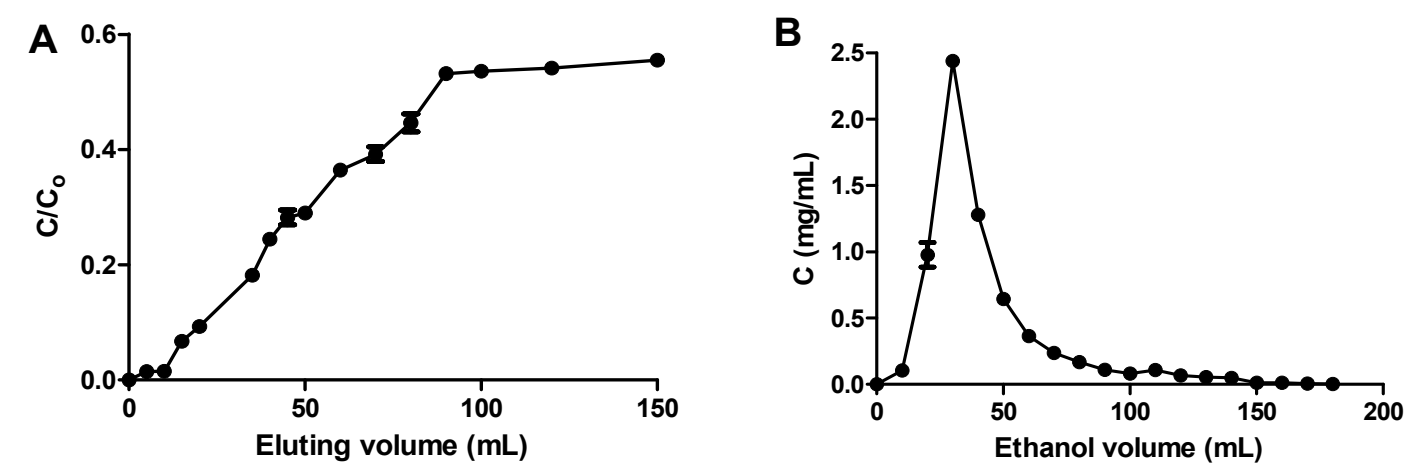

Figure 5. Dynamic breakthrough (A) and desorption (B) curves for OPL total flavonoids on XAD7HP.

The dynamic desorption curve for XAD7HP was plotted from the volume of the eluting desorption solution and the TFC of the desorbed solution. As displayed in Figure 5B, the OPL total flavonoids could be completely desorbed after elution with $180 \mathrm{~mL}$ of $80 \%$ aqueous ethanol. The eluted desorbed solution was pooled and evaluated for its TFC. The TFC value of the desorbed solution was 487.97 $\mathrm{mg}$ QCE/g, which was a 3.57-fold increase compared to the initial TFC of the original OPL extract of $136.69 \mathrm{mg}$ QCE/g.

\subsection{UHPLC-UV/PDA and UHPLC-MS/MS Analysis of Crude and Total Flavonoid-Enriched OPL Extracts}

Figure 6 reveals the comparison of compounds present in a crude extract and an extract after enrichment with XAD7HP macroporous resin. The peaks were putatively identified after analyzing the fragmentation pattern and UV-Vis absorption spectrum. The assigned peaks were cross-checked with previous literature reports that managed to extensively characterize the metabolites present in crude extract of oil palm leaves [7,27]. Table 3 lists 23 identified compounds ranging from sugar to organic acids, phenolic acids, and flavonoids that were found in crude OPL extract, while 14 of these compounds were found in enriched fraction at different concentration. The crude OPL extract contained sucrose, chelidonic acid dimer, citric acid, and several phenolic acids including dihydroxylbenzoyl-O-hexoside, hydroxylbenzoyl-O-hexoside, galloyl-O-hexoside, vanilloyl-O-hexoside, and sinapoyl-O-hexoside. These compounds were also reported by Tahir et al. [27]. The rest of the compounds present in crude OPL extract were flavonoids, specifically apigenin and luteolin derivatives [7]. 
Table 3. Putative identification of compounds present in crude extract and enriched fraction using UHPLC-UV/PDA and UHPLC-MS/MS analysis.

\begin{tabular}{|c|c|c|c|c|c|c|c|c|c|}
\hline \multirow{2}{*}{ Peak } & \multirow{2}{*}{$\begin{array}{l}t_{R} \\
(\min )\end{array}$} & \multirow{2}{*}{$\begin{array}{l}\lambda_{\max } \\
(\mathrm{nm})\end{array}$} & \multirow{2}{*}{$\underset{(m / z)}{[M-H]^{-}}$} & \multirow{2}{*}{ Formula } & \multirow{2}{*}{ Key MS/MS Fragments $(m / z)$} & \multirow{2}{*}{ Class } & \multirow{2}{*}{ Possible Compound } & \multicolumn{2}{|c|}{ Peak Intensity } \\
\hline & & & & & & & & Crude & Fraction \\
\hline 1 & 0.65 & 270 & 341.0850 & $\mathrm{C}_{12} \mathrm{H}_{22} \mathrm{O}_{11}$ & $161.0224,119.0327,113.0223,101.0223,89.0224$ & Sugar & Sucrose & + & - \\
\hline 2 & 0.71 & 268,374 & 366.9911 & $\mathrm{C}_{14} \mathrm{H}_{8} \mathrm{O}_{18}$ & $182.9911,139.0014,94.0276,67.0170$ & Organic acid & Chelidonic acid dimer & + & _- \\
\hline 3 & 0.83 & 258 & 191.0189 & $\mathrm{C}_{6} \mathrm{H}_{8} \mathrm{O}_{7}$ & $111.0066,87.0067,57.0328$ & Organic acid & Citric acid & ++ & - \\
\hline 4 & 0.93 & 312 & 315.0697 & $\mathrm{C}_{13} \mathrm{H}_{16} \mathrm{O}_{9}$ & $152.0092,109.0195$ & Phenolic acid & Dihydroxylbenzoyl-O-hexoside & + & - \\
\hline 5 & 0.96 & 288,310 & 299.0748 & $\mathrm{C}_{13} \mathrm{H}_{16} \mathrm{O}_{8}$ & $137.0222,93.0325$ & Phenolic acid & Hydroxylbenzoyl-O-hexoside & ++ & - \\
\hline 6 & $\begin{array}{l}0.90 \\
1.07\end{array}$ & 286,324 & 331.0645 & $\mathrm{C}_{13} \mathrm{H}_{16} \mathrm{O}_{10}$ & $168.0405,153.0170,125.0221$ & Phenolic acid & Galloyl-O-hexoside & t+ & - \\
\hline 7 & 1.84 & 286,324 & 329.0528 & $\mathrm{C}_{14} \mathrm{H}_{18} \mathrm{O}_{9}$ & $167.0326,153.0092,123.0440$ & Phenolic acid & Vanilloyl-O-hexoside & ++ & - \\
\hline 8 & 2.49 & 278 & 385.0744 & $\mathrm{C}_{17} \mathrm{H}_{22} \mathrm{O}_{10}$ & $223.0603,209.0279,191.0174,147.0272$ & Phenolic acid & Sinapoyl-O-hexoside & ++ & - \\
\hline 9 & 2.57 & 280,310 & 289.0717 & $\mathrm{C}_{15} \mathrm{H}_{14} \mathrm{O}_{6}$ & $205.0480,151.0378,137.0222,125.0222,109.0273$ & Catechin & Catechin isomer & + & - \\
\hline 10 & 3.17 & 272,348 & 609.1411 & $\mathrm{C}_{27} \mathrm{H}_{30} \mathrm{O}_{16}$ & $519.1104489 .0998,429.0786,399.0696,369.0585$ & Flavone & Luteolin-6,8-di-C-hexose & ++ & ++ \\
\hline 11 & 4.26 & 280,324 & 289.0717 & $\mathrm{C}_{15} \mathrm{H}_{14} \mathrm{O}_{6}$ & $205.0480,151.0378,137.0223,125.0222,109.0274$ & Catechin & Catechin isomer & + & + \\
\hline 12 & 4.88 & 272,336 & 593.1464 & $\mathrm{C}_{27} \mathrm{H}_{30} \mathrm{O}_{15}$ & $503.1155,473.1051,383.0739,353.0638$ & Flavone & Apigenin-6,8-di-C-hexose & ++ & +++ \\
\hline 13 & 6.72 & 272,346 & 609.1411 & $\mathrm{C}_{27} \mathrm{H}_{30} \mathrm{O}_{16}$ & $489.1001,429.0789,399.0679,369.0604$ & Flavone & Luteolin-6,8-di-C-hexose & ++ & + \\
\hline 14 & 7.10 & 272,334 & 563.1359 & $\mathrm{C}_{26} \mathrm{H}_{28} \mathrm{O}_{14}$ & $473.1053,443.0949,383.0742,353.0639$ & Flavone & Apigenin-6-C-pentose-8-C-hexose & + & ++ \\
\hline 15 & 7.86 & 270,348 & 447.0896 & $\mathrm{C}_{21} \mathrm{H}_{20} \mathrm{O}_{11}$ & $357.0588,339.0480,327.0483,297.0379,285.0381$ & Flavone & Isoorientin (Luteolin-6-C-hexose) & +++ & ++++ \\
\hline 16 & 8.52 & 272,336 & 563.1359 & $\mathrm{C}_{26} \mathrm{H}_{28} \mathrm{O}_{14}$ & $473.1051,443.0949,383.0741,353.0638$ & Flavone & Apigenin- 6 - $C$-hexose- 8 -C-pentose & +++ & ++++ \\
\hline 17 & 9.00 & 270,350 & 447.0896 & $\mathrm{C}_{21} \mathrm{H}_{20} \mathrm{O}_{11}$ & $357.0587,339.0476,327.0485,297.0378,285.0380$ & Flavone & Orientin (Luteolin-8-C-hexose) & +++ & +++ \\
\hline 18 & 9.87 & 270,348 & 593.1464 & $\mathrm{C}_{27} \mathrm{H}_{30} \mathrm{O}_{15}$ & $473.1049,429.0792,369.0590,357.0589,327.0485$ & Flavone & Luteolin-6-C-hexose- 8-C-deoxyhexose & ++ & +++ \\
\hline 19 & 11.22 & 274,334 & 563.1359 & $\mathrm{C}_{26} \mathrm{H}_{28} \mathrm{O}_{14}$ & $503.1168,473.1056,443.0950,383.0743,353.0639$ & Flavone & Apigenin-6-C-pentose-8-C-hexose & + & ++ \\
\hline 20 & 11.60 & 272,336 & 593.1464 & $\mathrm{C}_{27} \mathrm{H}_{30} \mathrm{O}_{15}$ & $473.1067,413.0846,369.0590,357.0589,293.0434$ & Flavone & Luteolin-6-C-hexose- 8-C-deoxyhexose & ++ & ++ \\
\hline 21 & 12.44 & 270,338 & 431.0947 & $\mathrm{C}_{21} \mathrm{H}_{20} \mathrm{O}_{10}$ & $341.0639,323.0529,311.0536,283.0589$ & Flavone & Vitexin (Apigenin-6-C-hexose) & ++ & ++++ \\
\hline 22 & 13.85 & 270,338 & 431.0947 & $\mathrm{C}_{21} \mathrm{H}_{20} \mathrm{O}_{10}$ & $341.0638,323.0536,311.0536,283.0588$ & Flavone & Isovitexin (Apigenin-8-C-hexose) & ++ & ++++ \\
\hline 23 & 17.19 & 270,338 & 577.1306 & $\mathrm{C}_{27} \mathrm{H}_{30} \mathrm{O}_{14}$ & $457.1098,413.0845,353.0630,341.0640,311.0536,293.0432$ & Flavone & Apigenin-6-C-hexose-8-C-deoxyhexose & ++ & +++ \\
\hline
\end{tabular}

$(-)=$ absence,$(+)=$ low intensity, $(++)=$ medium intensity, $(+++)=$ high intensity, and $(++++)=$ significantly high intensity. 


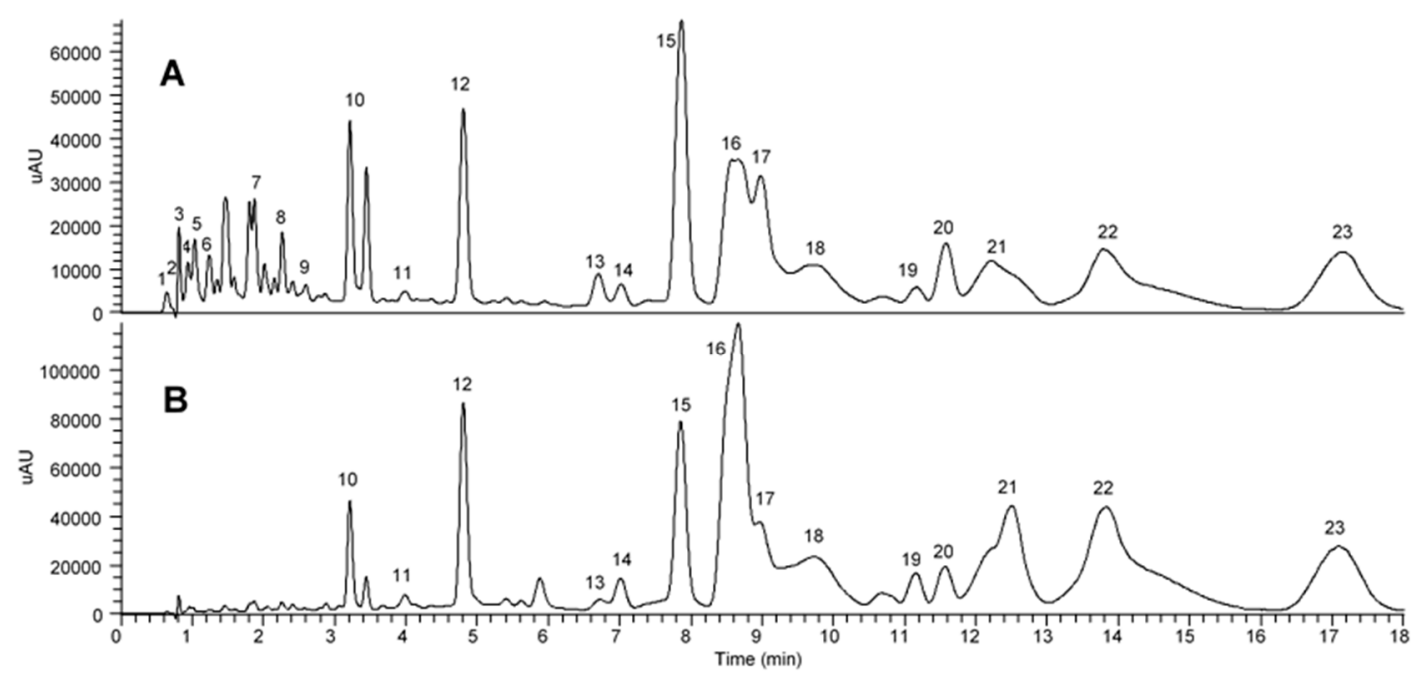

Figure 6. UHPLC-UV/PDA chromatograms of (A) crude OPL extract and (B) total flavonoid-enriched OPL extract at $340 \mathrm{~nm}$.

Interestingly, XAD7HP managed to enrich flavonoids present in oil palm leaves and selectively adsorbed apigenin and luteolin derivatives. This was obviously observed in Figure 6 and tabulated in Table 3, whereby the peaks labeled 1-9 were absent and some of the peak intensities of apigenin and luteolin derivatives were increased in comparison with crude OPL extract. including apigenin-6,8-di$C$-hexose, apigenin-6- $C$-pentose-8-C-hexose, isoorientin, apigenin-6-C-hexose-8- $C$-pentose, luteolin-6$C$-hexose-8-C-deoxyhexose, vitexin, isovitexin. and apigenin-6-C-hexose-8-C-deoxyhexose.

\subsection{Free Radical Scavenging Activities of Crude and Enriched Fraction of OPL}

The crude OPL extract and enriched total flavonoid fraction were tested in terms of their antioxidant activities by investigating their capability to inhibit free radicals, which is the main mechanism involved in antioxidant activity. The result is presented as $\mathrm{IC}_{50}$ (the concentration required to scavenge $50 \%$ of radical) of DPPH and NO free radical scavenging activities in Table 4. Both the crude OPL extract and the flavonoid-enriched fraction possessed good DPPH and NO free radical scavenging activities. However, one unanticipated finding was that the crude OPL which contained total flavonoid of 136.69 mg QCE/g dried extract had better antioxidant capacities than the enriched total flavonoid fraction with $487.97 \mathrm{mg}$ QCE/g dried extract, showing a lower $\mathrm{IC}_{50}$ of $15.88 \mu \mathrm{g} / \mathrm{mL}$ in comparison with the $\mathrm{IC}_{50}$ of enriched fraction, $59.48 \mu \mathrm{g} / \mathrm{mL}$. The results were consistent with NO free radical scavenging activity, whereby the crude OPL extract had a higher antioxidant activity with an $\mathrm{IC}_{50}$ value of $17.84 \mu \mathrm{g} / \mathrm{mL}$, while the enriched fraction reached $\mathrm{IC}_{50}$ at $68.13 \mu \mathrm{g} / \mathrm{mL}$. The appropriate explanation for this is due to the synergistic or additive effects. The crude OPL extract contains a wide range of phytochemicals ranging from groups of sugar moieties to phenolic acids, flavonoid glycosides, catechin stereoisomers, fatty acids, organic acids, amino acids, etc. [7,28,29]. Some of these common compounds such as catechin, citric acid, isoorientin, orientin, etc. are well known as having high antioxidative effects; hence, the interaction between these antioxidant constituents can create synergistic or additive effects on scavenging free radicals $[27,30]$, resulting in higher antioxidant activity. 
Table 4. TFC and DPPH free radical scavenging activity $\left(\mathrm{IC}_{50}\right)$ of OPL extract and enriched OPL fraction.

\begin{tabular}{cccc}
\hline \multirow{2}{*}{ Sample } & \multirow{2}{*}{ TFC $(\mathrm{mg}$ QCE/g Dried Extract) } & \multicolumn{2}{c}{ Antioxidant Activity $\left(\mathrm{IC} \mathbf{5 0}_{\mathbf{5 0}} \boldsymbol{\mu g} / \mathrm{mL}\right)$} \\
\cline { 3 - 4 } & & DPPH & NO \\
\hline OPL extract & $136.6896^{\mathrm{a}} \pm 0.3106$ & $15.8767^{\mathrm{a}} \pm 2.8610$ & $17.8367^{\mathrm{a}} \pm 3.3301$ \\
\hline Enriched total flavonoid fraction & $487.9729^{\mathrm{b}} \pm 0.9748$ & $59.4767^{\mathrm{b}} \pm 4.4895$ & $68.1300^{\mathrm{b}} \pm 7.1184$ \\
\hline
\end{tabular}

Values labelled with the different letters ( $\mathrm{a}$ and $\mathrm{b})$ are significantly $(p<0.05)$ different between OPL extract and enriched total flavonoid fraction.

Meanwhile, the macroporous resin was created to selectively adsorb on the compounds present in crude OPL extracts; hence, this study showed that XAD7HP resins tend to adsorb on compounds that have similar characteristics, i.e., flavonoids. There are different groups of flavonoids present in OPL extracts which can be classified into flavone, flavonol, isoflavone, flavanone, etc. [7,29,31]. Although some of these flavonoids such as epicatechin, quercetin, rutin, luteolin, etc. were found to contain a high percentage of free radical inhibition, some of the flavonoids were reported to be poor free radical scavengers such as vitexin and isovitexin [32]. Hence, the combination of these flavonoids could not generate a significant effect on DPPH free radical scavenging activity as compared to the crude OPL extracts. Therefore, the findings could not conclude that the flavonoid-enriched fraction had lower antioxidant capacity than crude OPL extracts solely based on DPPH and NO free radical scavenging activities. Different antioxidants follow different mechanisms or pathways under various stressed conditions in order to show their antioxidative response [27]. Further research should be done to investigate the other mechanisms or pathways of these extracts in expressing their antioxidative response, such as other radical chain reaction inhibitors (FRAP, ABTS, ORAC), metal chelators, quenching single oxygen species, protein/enzymes, antioxidant enzyme cofactors, etc. [27,33-35].

\subsection{Adsorption Mechanism}

The adsorption and desorption capacity of total flavonoids from MARs is related to several factors including surface area, average pore size, particle diameter, and polarity [35]. The surface area of XAD7HP $\left(380 \mathrm{~m}^{2} / \mathrm{g}\right)$ is between that of XAD4 $\left(750 \mathrm{~m}^{2} / \mathrm{g}\right)$ and DAX-8 $\left(140 \mathrm{~m}^{2} / \mathrm{g}\right)$. The particle diameters of XAD7HP and XAD4 are the same $(0.250-0.841 \mathrm{~mm})$, while DAX-8 is lower than both with a particle diameter of $0.250-0.420 \mathrm{~mm}$. The average pore size of XAD7HP is the largest (300-400 $\AA$ ) among the tested MARs, followed by DAX-8 (225 $\AA$ ) and XAD4 (100 $)$. The matrix of XAD4 is made of styrene-divinylbenzene, while XAD7HP and DAX-8 are made of acrylic and acrylic ester, respectively. Based on the results obtained, XAD7HP showed the highest adsorption and desorption capacities followed by DAX- 8 and XAD4, indicating that large average pore diameter (300-400 $\mathrm{A}$ ), medium surface area $\left(380 \mathrm{~m}^{2} / \mathrm{g}\right)$, and acrylic matrix are the most appropriate properties of MARs for entrapment and release of total flavonoids in OPL extracts.

In addition, the polarity of MARs plays the most vital role in the sorption process. Both XAD7HP and DAX-8 are moderate polar MARs, while XAD4 is a non-polar resin. The results indicated that moderate polar resins (XAD7HP and DAX-8) are most suitable to adsorb and desorb total flavonoids from OPL in comparison to the non-polar resin (XAD4). The polarity matching between OPL extract and moderate polar XAD7HP is mainly attributed to the hydrogen bonding and van der Waals interactions [36-38]. Firstly, the flavonoid structures contain several hydroxyl groups that can interact with XAD7HP through hydrogen bonding, which is a specific intra-molecular or inter-molecular interaction. Secondly, the van der Waals forces from the aqueous solvent system became the main driving force for polymeric XAD7HP in the sorption process. Therefore, the combination of these interactions contributes significantly to the adsorption and desorption processes, as indicated by the high adsorption/desorption capacities. 


\section{Materials and Methods}

\subsection{Chemicals and Reagents}

Purified water was obtained from a Milli-Q system (Millipore Lab, Bedford, MA, USA). Sodium acetate, phosphoric acid, quercetin, sulfanilamide, and N-(1-naphthyl) ethylenediamine dihydrochloride were provided by Sigma (Aldrich, Germany). Aluminum chloride was purchased from HmbG Chemicals (Hamburg, Germany). Hydrochloric acid, dimethyl sulfoxide (DMSO), and sodium hydroxide were purchased from Merck (Darmstadt, Germany), whereas 95\% ethanol was obtained from R\&M Chemicals (Essex, United Kingdom). Sodium nitroprusside was purchased from Bendosen Laboratory Chemical (Bendosen, Norway).

\subsection{Adsorbents and Pretreatment}

Macroporous resins (Amberlite ${ }^{\circledR}$ XAD4, Amberlite ${ }^{\circledR}$ XAD7HP, and Supelite ${ }^{\mathrm{TM}}$ DAX-8) were purchased from Sigma (Aldrich, Germany). The physical properties of these resins are summarized in Table 5. To remove monomers and porogenic agents trapped inside the pores, the resins were soaked in $95 \%$ ethanol at a resin/solvent ratio of 1:20 for $24 \mathrm{~h}$. The resins were then washed with deionized water and soaked again in $1 \mathrm{M}$ sodium hydroxide for another $24 \mathrm{~h}$ after several washes with deionized water; then, the resins were soaked in $1 \mathrm{M}$ hydrochloric acid for $24 \mathrm{~h}$ and washed again with deionized water. The resins were dried $\left(60^{\circ} \mathrm{C}\right)$ in a universal drying oven (model 100-800, Memmert, Schwabach, Germany) until constant weight was observed.

Table 5. Physical properties of the selected macroporous resins.

\begin{tabular}{cccccc}
\hline Type & $\begin{array}{c}\text { Surface Area } \\
\left(\mathbf{m}^{2} / \mathbf{g}\right)\end{array}$ & $\begin{array}{c}\text { Particle Diameter } \\
\mathbf{( m m})\end{array}$ & $\begin{array}{c}\text { Average Pore } \\
\text { Diameter }(\mathbf{A})\end{array}$ & Matrix & Polarity \\
\hline Amberlite $^{\circledR}$ XAD4 & 750 & $0.250-0.841$ & 100 & Styrene-divinylbenzene & Non-polar \\
Amberlite $^{\circledR}$ XAD7HP & 380 & $0.250-0.841$ & $300-400$ & Acrylic & Moderate polar \\
Supelite $^{\mathrm{TM}}$ DAX-8 & 140 & $0.250-0.420$ & 225 & Acrylic ester & Moderate polar \\
\hline
\end{tabular}

\subsection{Preparation of OPL Extract}

Mature OPLs were harvested from University Agricultural Park, Universiti Putra Malaysia (UPM). A voucher specimen (SK 3332/18) of the plant material was authenticated and deposited in the Herbarium of Institute of Bioscience, UPM. The leaflets were cut into small pieces of approximately 2.54 $\mathrm{cm}$ (an inch length) in size, and subjected to oven-drying at $35^{\circ} \mathrm{C}$ until constant weight was observed. The dried OPLs were ground into fine powder, mixed with methanol/water (4:1), and vortexed at 3000 rpm for $30 \mathrm{~s}$. The mixture was then sonicated for a further $30 \mathrm{~min}$ in an ultrasonic water bath (Branson 2510MT Ultrasonic Cleaner, Darmstadt, Germany) with a frequency of $40 \mathrm{~Hz}$ at $25^{\circ} \mathrm{C}$. The mixture was centrifuged at $4000 \mathrm{rpm}$ for $15 \mathrm{~min}$. After separation, the supernatant was concentrated using a rotary evaporator (Heidolph Instruments GmbH and Co.KG, Schwabach, Germany). The OPL extract was then freeze-dried using Labconco ${ }^{\circledR}$ FreeZone Freeze Drier System (Kansas, MO, USA) for complete moisture removal.

\subsection{Determination of Total Flavonoid Content}

The total flavonoid content (TFC) of OPL extract samples (initial and after resin treatment) was determined using the aluminum chloride complex colorimetric assay as previously described by Formagio et al. [39], with some modifications. Test sample solutions $(0.1 \mathrm{mg} / \mathrm{mL})$ were prepared in methanol. For measurement, a $125-\mu \mathrm{L}$ aliquot of the test sample solution was mixed with $375 \mu \mathrm{L}$ of $95 \%$ ethanol, $25 \mu \mathrm{L}$ of $10 \%$ aluminum chloride solution, $25 \mu \mathrm{L}$ of $1 \mathrm{M}$ sodium acetate solution, and $700 \mu \mathrm{L}$ of distilled water in a $2-\mathrm{mL}$ microcentrifuge tube. The reaction mixture was vortexed and incubated at $25^{\circ} \mathrm{C}$ in an orbital shaker at a speed of $100 \mathrm{rpm}$ for $40 \mathrm{~min}$. The absorbance of the mixture was then recorded at $415 \mathrm{~nm}$ on a Tecan Infinite F200 Pro plate reader (Tecan Group Ltd., Männedorf, 
Switzerland). The analysis was carried out in triplicate, and the results were expressed in milligrams of quercetin equivalent per gram of extract (mg QCE/g extract).

\subsection{Static Adsorption and Desorption Experiments}

\subsubsection{Adsorption Kinetics of OPL Total Flavonoids on the Selected MARs}

To investigate the adsorption and desorption kinetics of each of the selected MARs on OPL total flavonoids, a specific procedure was followed. The accurately weighed resin $(0.1 \mathrm{~g})$ mixed with 5 $\mathrm{mL}$ OPL extract solution was placed in a $15-\mathrm{mL}$ centrifuge tube, tightly capped and carefully sealed, placed horizontally in a WiseCube WIG-10RL Precise Shaking Incubator (Wisd Laboratory Instruments, Wertheim, Germany), set to a shaking speed of $150 \mathrm{rpm}$. The adsorption process was conducted over $24 \mathrm{~h}$ at $25^{\circ} \mathrm{C}$. The experiment was carried out on OPL extract solutions of different $\mathrm{pH}(5,7$, and 9; adjusted with $1 \mathrm{M} \mathrm{HCl}$ or $1 \mathrm{M} \mathrm{NaOH}$ ), in triplicate. At $0,5,10,15,20,25,30,40,50,60,120,180,240$, $300,360,480$, and $1440 \mathrm{~min}$ time points, $0.125-\mathrm{mL}$ aliquots of the treated OPL extract were withdrawn for TFC determination. The adsorption kinetics equation for each resin was accordingly established for each.

\subsubsection{Adsorption Thermodynamics of OPL Total Flavonoids on the Selected MARs}

To investigate the adsorption thermodynamics of each of the selected MARs on OPL total flavonoids, a specific procedure was followed. Five different $15-\mathrm{mL}$ centrifuge tubes containing the accurately weighed resin $(0.1 \mathrm{~g})$ were firstly prepared. The resin in each tube was mixed with $5 \mathrm{~mL}$ of OPL extract solution (adjusted to $\mathrm{pH} 7$ ) of different concentrations $(5,2.5,1.25,0.625$, and $0.313 \mathrm{mg} / \mathrm{mL}$, respectively), capped and sealed as before, and placed horizontally in a WiseCube WIG-10RL Precise Shaking Incubator, set to a shaking speed of $150 \mathrm{rpm}$. The adsorption process was conducted over $24 \mathrm{~h}$, at different temperatures $\left(25,35,45\right.$, and $\left.55^{\circ} \mathrm{C}\right)$ in triplicate. At the end of the experiment, aliquots of $0.125 \mathrm{~mL}$ of the reaction mixtures were withdrawn for TFC determination. The adsorption thermodynamics for each resin was accordingly established for each.

\subsubsection{Static Desorption of OPL Total Flavonoids from the Selected MARs}

The adsorption experiment was repeated, separately for each resin, using the optimized conditions ( $\mathrm{pH}$, concentration, temperature, and time). As before, the experiments were conducted in $15-\mathrm{mL}$ centrifuge tubes containing the accurately weighed resin $(0.1 \mathrm{~g})$. After reaching adsorption equilibrium, excess solutions were removed from each tube, followed by the addition of aqueous ethanol solutions of various concentrations $(20 \%, 40 \%, 60 \%, 80 \%$, and $95 \%)$ for the desorption process. Desorption was again performed in the WiseCube WIG-10RL Precise Shaking Incubator, set to a shaking speed of $150 \mathrm{rpm}$, at $25^{\circ} \mathrm{C}$, for $24 \mathrm{~h}$. At the end of the experiment, aliquots of $0.125 \mathrm{~mL}$ of the reaction mixtures were withdrawn for TFC determination. The desorption capacity was calculated, and desorption ratio vs. solvent concentration plots were established for each resin, accordingly.

\subsection{Dynamic Sorption Experiments}

Dynamic adsorption and desorption experiments were carried out on a glass column $(2.5 \mathrm{~cm} \times 46 \mathrm{~cm})$ wet-packed with $4.4 \mathrm{~g}$ (dry weight) of the selected resin (200 $\mathrm{mL}$ bed volume) at room temperature. A $5 \mathrm{mg} / \mathrm{mL}$ OPL extract solution was prepared by dissolving $750 \mathrm{mg}$ of the extract in $150 \mathrm{~mL}$ of deionized water. The solution was filtered, adjusted to $\mathrm{pH}$ 7, and cautiously introduced and eluted through the column. Then, 10-mL eluates were collected and their TFC determined as before. The breakthrough and the saturation points are represented by $5 \%$ and $95 \%$, respectively, of the ratio of the TFC of the eluting volume to the TFC of the original OPL extract $\left(C / C_{0}\right)$. The adsorbed column was then washed with $30 \mathrm{~mL}$ of deionized water and then eluted with aqueous ethanol at the optimized concentration, at a constant flow rate of $0.3 \mathrm{~mL} / \mathrm{min}$. Then, $10-\mathrm{mL}$ eluates were collected and their TFC determined as before. The dynamic sorption experiments were all carried out in triplicate. 


\subsection{Equations Used in This Study}

The adsorption/desorption capacities, kinetics, and thermodynamics model equations applied in this study were as follows:

$$
\begin{gathered}
\text { The adsorption capacity : } q_{e}=\frac{C_{o}-C_{e}}{W} \times V \\
\text { The desorption capacity : } q_{d}=\frac{C_{d} V_{d}}{W} \\
\text { The desorption ratio : } D=\frac{C_{d} V_{d}}{\left(C_{o}-C_{e}\right) V} \times 100
\end{gathered}
$$

The pseudo - first - order kinetics model $: \ln \left(q_{e}-q_{t}\right)=-k t+\ln q_{e}$

$$
\text { The pseudo - second - order kinetics model : } \frac{t}{q_{t}}=\frac{1}{k_{2} q_{e}^{2}}+\frac{t}{q_{e}}
$$

The particle diffusion kinetics model : $q_{t}=k_{p} \cdot t^{\frac{1}{2}}+C$

The Langmuir equation and its variable form : $\frac{C_{e}}{q_{e}}=\frac{K_{L}}{q_{m}}+\frac{C_{e}}{q_{m}}$

The Freundlich equation and its variable form : $q e=K_{f} C_{e} \frac{1}{n}$

The Van's Hoff equation for enthalpy change $(\Delta \mathrm{H}): \ln K=-\frac{\Delta H}{R T}+A$.

Here, $q_{t}, q_{e}$, and $q_{m}$ are, respectively, the adsorption capacity at time $t$, the equilibrium adsorption capacity, and the maximum capacity to form a monolayer, measured as $\mathrm{mg} / \mathrm{g}$ dry resin. $C_{0}, C_{e}$, and $C_{d}$ are, respectively, the initial concentration, equilibrium concentration, and concentration in desorption solution $(\mathrm{mg} / \mathrm{mL}) . V$ is the volume $(\mathrm{mL})$ of initial solution, $V_{d}$ is the volume of the desorption solution $(\mathrm{mL})$, and $W$ is the dry weight $(\mathrm{g})$ of the resin used. $q_{d}$ is the desorption capacity, while $D$ is the desorption ratio (\%). $k_{1}, k_{2}$, and $k_{p}$ are the respective rate constants of pseudo-first-order, pseudo-second-order, and particle diffusion kinetic models of adsorption. $C$ is the constant for the particle diffusion kinetics model. $K_{L}$ is the affinity parameter between resins and flavonoids $(\mathrm{mL} / \mathrm{mg})$. $K_{f}$ is the adsorption capacity of the resins, and $1 / n$ is the adsorption intensity of the resins. $R$ is the universal gas constant $\left(8.314 \mathrm{~J} \cdot \mathrm{mol}^{-1} \cdot \mathrm{K}^{-1}\right)$. $T$ is the absolute temperature $(\mathrm{K})$, and $\mathrm{A}$ is a constant. The Langmuir and Freundlich equations were used to describe the adsorption equilibrium and linearity fitting of each equation.

\subsection{UHPLC-UV/PDA and UHPLC-MS/MS Analysis of Crude and Total Flavonoid-Enriched Extracts}

Crude and total flavonoid-enriched OPL extracts were separated using a $\mathrm{C}_{18}$ reversed-phase Acquity UPLC ${ }^{\circledR}$ BEH column $(1.7 \mu \mathrm{m}$ particle size and $2.1 \mathrm{~mm}$ i.d. $\times 100 \mathrm{~mm}$ length) from Waters (Wexford, Ireland) on a Thermo Scientific Ultimate 3000 with a PDA-3000 photodiode array detector and a thermostat column compartment which was maintained at $25^{\circ} \mathrm{C}$ during UHPLC analysis. Gradient elution was performed with water $/ 0.1 \%$ formic acid $/ 0.063 \%$ ammonium formate (solvent A) and acetonitrile $/ 0.1 \%$ formic acid (solvent $\mathrm{B}$ ). The program gradient proceeded using the following sequence of solvent B percentages: $10 \%$ for $0-0.6 \mathrm{~min}, 10 \%-11 \%$ for $0.6-1.0 \mathrm{~min}, 11 \%-11.3 \%$ for $1.0-1.5$ $\mathrm{min}, 11.3 \%$ for $1.5-5.5 \mathrm{~min}, 11.3 \%-11.4 \%$ for $5.5-8.0 \mathrm{~min}, 11.4 \%-11.8 \%$ for $8.0-8.2 \mathrm{~min}, 11.8 \%-12 \%$ for $8.2-12.0 \mathrm{~min}, 12 \%-10 \%$ for $12.0-13.0 \mathrm{~min}$, and $10 \%$ for $13.0-18.0 \mathrm{~min}$. The flow rate was constant at $0.40 \mathrm{~mL} / \mathrm{min}$. The UV detector was set to $340 \mathrm{~nm}$. The extracts were prepared as $5 \mathrm{mg} / \mathrm{mL}$ and filtered through a $0.22-\mu \mathrm{m}$ syringe filter (Sartorius AG, Goettingen, Germany) for UHPLC injection.

After going through the UV/PDA detector, the flow was split to allow only $200 \mu \mathrm{L} / \mathrm{min}$ of eluent into the electrospray ionization (ESI) source of MS. The MS analysis was done on a Q-Exactive Focus Orbitrap LC-MS/MS system. The eluent was monitored by ESI-MS under negative mode scanned 
from $\mathrm{m} / \mathrm{z} 67.9$ to 1000 . ESI was conducted using a spray voltage of $4.2 \mathrm{kV}$. High-purity nitrogen gas was used as dry gas at a sheath gas flow rate of 40 (arbitrary units) and aux gas flow rate of 8 (arbitrary units). The capillary temperature was set at $320^{\circ} \mathrm{C}$, while the aux gas heater temperature was set at $0{ }^{\circ} \mathrm{C}$. The peaks were assigned based on their molecular weights, fragmentation patterns, and maximum wavelengths with additional support from previous studies and standard online databases (freely available), such as the Human Metabolome Database (HMDB) at http://www.hmdb.ca/, and PubChem at https://pubchem.ncbi.nlm.nih.gov/. The peaks were compared between the crude and total flavonoid-enriched extracts based on peak intensity. The peak intensity was classified based on the area under the curve.

\subsection{Determination of DPPH Free Radical Scavenging Activity}

The 1,1-diphenyl-2-picrylhydrazyl (DPPH) free radical scavenging assay was performed as described earlier by Lee et al. [40], with some modifications. Test concentrations of the OPL extract ranging from 0.7 to $100 \mu \mathrm{g} \cdot \mathrm{mL}^{-1}$ were prepared by serial dilutions of a $0.1 \mathrm{mg} / \mathrm{mL}$ stock solution. A $50-\mu \mathrm{L}$ aliquot of the test solution was mixed with $100 \mu \mathrm{L}$ of DPPH $\left(5.9 \mathrm{mg} \cdot 100 \mathrm{~mL}^{-1}\right)$, mixed well and incubated in the dark. After $30 \mathrm{~min}$, the absorbance was measured at $515 \mathrm{~nm}$ using a Tecan Infinite F200 Pro plate reader (Tecan Group Ltd., Männedorf, Switzerland). Scavenging activity (SA) was calculated according to the following equation:

$$
\mathrm{SA} \%=\left(\left(\mathrm{A}_{\mathrm{o}}-\mathrm{A}_{\mathrm{s}}\right) / \mathrm{A}_{\mathrm{o}}\right) \times 100 \%
$$

where $A_{o}$ is the absorbance of the blank, and $A_{s}$ is the absorbance of the test sample.

The assay was carried out in triplicate, and results were stated as $\mathrm{IC}_{50}$ value in $\mu \mathrm{g} \cdot \mathrm{mL}^{-1}$. Quercetin was used as a positive control in the assay.

\subsection{Determination of Nitric Oxide (NO) Free Radical Scavenging Activity}

The nitric oxide (NO) free radical scavenging assay was conducted according to Abdul-Hamid et al. [41], with some modifications. Basically, $1 \mathrm{mg}$ of OPL extract was weighed and transferred into $1 \mathrm{~mL}$ of dimethyl sulfoxide (DMSO), followed by dilution with DMSO to reach final concentrations ranging from 0.98 to $1000 \mu \mathrm{g} \cdot \mathrm{mL}^{-1}$. A $60-\mu \mathrm{L}$ aliquot of the test solution was mixed with $60 \mu \mathrm{L}$ of sodium nitroprusside ( $0.05236 \mathrm{~g}$ dissolved in $20 \mathrm{~mL}$ of $10 \mathrm{mM}$ phosphate buffer saline), mixed well and incubated at $298 \mathrm{~K}$ for $150 \mathrm{~min}$. After incubation, $60 \mu \mathrm{L}$ of Griess reagent (a mixture of 0.1 $\mathrm{g}$ of sulfanilamide, $0.01 \mathrm{~g}$ of $\mathrm{N}$-(1-naphthyl) ethylenediamine dihydrochloride, and $10 \mathrm{~mL}$ of $2.5 \%$ phosphoric acid) was added into the reaction mixture, and the absorbance was measured at $550 \mathrm{~nm}$ using a Tecan Infinite F200 Pro plate reader (Tecan Group Ltd., Männedorf, Switzerland). Quercetin was used as a positive control in the assay. Scavenging activity (SA) was calculated according to the equation 11.

The assay was carried out in triplicate, and results were stated as $\mathrm{IC}_{50}$ value in $\mu \mathrm{g} \cdot \mathrm{mL}^{-1}$. Quercetin was used as a positive control in the assay.

\subsection{Statistical Analysis}

Minitab statistical software (Version 16, Minitab Inc, State College, PA, USA) and InStat V2.02 statistical package (GraphPad Software, San Diego, CA, USA) were used for all statistical analyses. The results were presented as means \pm standard deviation with three replications. One-way analysis of variance (ANOVA) completed by Tukey's test was applied to perform analyses to determine significant differences. The significant level was set to $p<0.05$.

\section{Conclusions}

In this investigation, the first attempt of the evaluation of the sorption properties of three MARs for total flavonoids from oil palm (Elaeis guineensis Jacq.) mature leaf extracts was reported. The 
static adsorption data were analyzed with empirical equations, indicating that the kinetic data fit the pseudo-second-order kinetic model, while the isotherms could be properly explained by the Freundlich isotherm model. The adsorption of the respective resins was an exothermic and experienced physical adsorption process. Furthermore, XAD7HP and 80\% aqueous ethanol were selected in the dynamic sorption studies as optimal adsorbent and desorbing solvent, respectively. After treating with XAD7HP packed in a glass column, the TFC enhanced from 136.69 to $487.97 \mathrm{mg}$ QCE/g with a 3.57-fold increment. Moreover, UHPLC-UV/PDA and UHPLC-MS/MS analysis revealed that apigenin and luteolin derivatives were selectively adsorbed by XAD7HP. In addition, both the crude OPL extract and the flavonoid-enriched fraction possessed good DPPH and NO free radical scavenging activities. Strong hydrogen bonding and van der Waals forces between the flavonoids and cross-linked polymeric XAD7HP resin explained the findings. With this knowledge, a simple yet efficient method in the enrichment of total flavonoids from agricultural waste was developed. As a result, the enriched fraction of these total flavonoids can be formulated into healthcare products and foodstuff for improving human health, especially in combating diseases proven to be treatable with bioactive total flavonoids.

Author Contributions: K.S. and M.S.C.Z. conceptualized and designed the experiments; K.S. provided the research materials; M.S.C.Z. performed the experiments and wrote the manuscript; K.S., M.S.C.Z., and C.Y.T. analyzed the data; K.S., S.Y.L., and C.Y.T. validated the data and edited the manuscript. All authors have read and agree to the published version of the manuscript.

Funding: This research received no external funding.

Acknowledgments: The first author gratefully acknowledges Universiti Putra Malaysia for awarding a Graduate Research Fellowship (GRF).

Conflicts of Interest: The authors declare no conflict of interest.

\section{References}

1. Hartley, C.W.S. The Oil Palm (Elaeis Guineensis Jacq.) Tropical Agriculture Series, 3rd ed.; Longman Scientific \& Technical: London, UK, 1988; p. 761.

2. Zeven, A.C. On the origin of the oil palm (elaeis guineensis jacq). Grana Palynol. 1964, 5, 121-123. [CrossRef]

3. Schnell, R.J.; Priyadarshan, P.M. Genomics of Tree Crops; Springer: New York, NY, USA, 2012.

4. Owoyele, B.V.; Owolabi, G.O. Traditional oil palm (Elaeis guineensis jacq.) and its medicinal uses: A review. Tang Humanit. Med. 2014, 416, 16. [CrossRef]

5. Mohamed, S. Oil Palm Leaf: A New Functional Food Ingredient for Health and Disease Prevention. J. Food Process. Technol. 2014, 5, 2. [CrossRef]

6. Jaffri, J.M.; Mohamed, S.; Ahmad, I.N.; Mustapha, N.M.; Manap, Y.A.; Rohimi, N. Effects of catechin-rich oil palm leaf extract on normal and hypertensive rats' kidney and liver. Food Chem. 2011, 128, 433-441. [CrossRef] [PubMed]

7. Tahir, N.I.; Shaari, K.; Abas, F.; Parveez, G.K.A.; Ishak, Z.; Ramli, U.S. Characterization of apigenin and luteolin derivatives from oil palm (Elaeis guineensis Jacq.) Leaf using LC-ESI-MS/MS. J. Agric. Food Chem. 2012, 60, 11201-11210. [CrossRef]

8. Xiao, J.; Capanoglu, E.; Jassbi, A.R.; Miron, A. Advance on the Flavonoid C-glycosides and Health Benefits. Crit. Rev. Food Sci. Nutr. 2016, 56, S29-S45. [CrossRef]

9. Grand View Research. Flavonoids Market Size To Reach \$1.06 Billion By 2025; Grand View Research Inc.: San Francisco, CA, USA, 2016.

10. Wu, S.; Wang, Y.; Gong, G.; Li, F.; Ren, H.; Liu, Y. Adsorption and desorption properties of macroporous resins for flavonoids from the extract of Chinese wolfberry (Lycium barbarum L.). Food Bioprod. Process. 2015, 93, 148-155. [CrossRef]

11. Wan, P.; Sheng, Z.; Han, Q.; Zhao, Y.; Cheng, G.; Li, Y. Enrichment and purification of total flavonoids from Flos Populi extracts with macroporous resins and evaluation of antioxidant activities in vitro. J. Chromatogr. B Anal. Technol. Biomed. Life Sci. 2014, 945-946, 68-74. [CrossRef]

12. Li, C.; Zheng, Y.; Wang, X.; Feng, S.; Di, D. Simultaneous separation and purification of flavonoids and oleuropein from Olea europaea L. (olive) leaves using macroporous resin. J. Sci. Food Agric. 2011, 91, 2826-2834. [CrossRef] 
13. Dong, Y.; Zhao, M.; Sun-Waterhouse, D.; Zhuang, M.; Chen, H.; Feng, M.; Lin, L. Absorption and desorption behaviour of the flavonoids from Glycyrrhiza glabra L. leaf on macroporous adsorption resins. Food Chem. 2015, 168, 538-545. [CrossRef]

14. Huang, S.; Lin, B.; Li, B.; Tan, B.; Hong, Y. Purification of total flavonoids from loquat leaves by macroporous resin and corresponding antioxidant capacity. BIO Web Conf. 2017, 8, 3010. [CrossRef]

15. Lou, S.; Chen, Z.; Liu, Y.; Ye, H.; Di, D. Synthesis of functional adsorption resin and its adsorption properties in purification of flavonoids from Hippophae rhamnoides L. leaves. Ind. Eng. Chem. Res. 2012, 51, 2682-2696. [CrossRef]

16. Scordino, M.; Di Mauro, A.; Passerini, A.; Maccarone, E. Adsorption of Flavonoids on Resins: Cyanidin 3-Glucoside. J. Agric. Food Chem. 2004, 52, 1965-1972. [CrossRef] [PubMed]

17. Du, H.; Wang, H.; Yu, J.; Liang, C.; Ye, W.; Li, P. Enrichment and purification of total flavonoid C-glycosides from abrus mollis extracts with macroporous resins. Ind. Eng. Chem. Res. 2012, 51, 7349-7354. [CrossRef]

18. Zhang, L.; Wu, T.; Xiao, W.; Wang, Z.; Ding, G.; Zhao, L. Enrichment and Purification of Total Ginkgo Flavonoid O-Glycosides from Ginkgo Biloba Extract with Macroporous Resin and Evaluation of Anti-Inflammation Activities In Vitro. Molecules 2018, 23, 1167. [CrossRef]

19. Ayranci, E.; Hoda, N. Adsorption kinetics and isotherms of pesticides onto activated carbon-cloth. Chemosphere 2005, 60, 1600-1607. [CrossRef]

20. Lorenc-Grabowska, E.; Gryglewicz, G. Adsorption of lignite-derived humic acids on coal-based mesoporous activated carbons. J. Colloid Interface Sci. 2005, 284, 416-423. [CrossRef]

21. Langmuir, I. The adsorption of gases on plane surfaces of glass, mica and platinum. J. Am. Chem. Soc. 1918, 40,1361-1403. [CrossRef]

22. Hall, K.R.; Eagleton, L.C.; Acrivos, A.; Vermeulen, T. Pore and Solid Diffusion Kinetics in Fixed-Bed Adsorption Under Constant Pattern Conditions. IEEC Fundam. 1966, 5, 212-223.

23. Wang, R.; Peng, X.; Wang, L.; Tan, B.; Liu, J.; Feng, Y.; Yang, S. Preparative purification of peoniflorin and albiflorin from peony rhizome using macroporous resin and medium-pressure liquid chromatography. $J$. Sep. Sci. 2012, 35, 1985-1992. [CrossRef]

24. Gökmen, V.; Serpen, A. Equilibrium and kinetic studies on the adsorption of dark colored compounds from apple juice using adsorbent resin. J. Food Eng. 2002, 53, 221-227. [CrossRef]

25. Lin, L.; Zhao, H.; Dong, Y.; Yang, B.; Zhao, M. Macroporous resin purification behavior of phenolics and rosmarinic acid from Rabdosia serra (MAXIM.) HARA leaf. Food Chem. 2012, 130, 417-424. [CrossRef]

26. Cao, S.-Q.; Pan, S.-Y.; Yao, X.-L.; Fu, H.-F. Isolation and Purification of Anthocyanins from Blood Oranges by Column Chromatography. Agric. Sci. China 2010, 9, 207-215. [CrossRef]

27. Tahir, N.I.; Saari, K.; Abas, F.; Parveez, A.; Tarmizi, H.A.; Ramli, U. Identification of Oil Palm (Elaeis Guineensis) Spear Leaf Metabolites Using Mass Spectrometry and Neutral Loss Analysis. J. Oil Palm Res. 2013, 25, 72-83.

28. Vargas, L.H.G.; Neto, J.C.R.; de Aquino Ribeiro, J.A.; Ricci-Silva, M.E.; Souza, M.T.; Rodrigues, C.M.; Abdelnur, P.V.; Ribeiro, J.A.D.A.; De Oliveira, A.E. Metabolomics analysis of oil palm (Elaeis guineensis) leaf: Evaluation of sample preparation steps using UHPLC-MS/MS. Metabolomics 2016, 12, 1-12. [CrossRef]

29. Sonam, K.S.; Guleria, S. Synergistic antioxidant activity of natural product. Anna Pharmacol Pharma. 2017, 2, 1-6.

30. Alzamora, S.M.; Tapia, M.S.; Chanes, J.W. New strategies for minimally processed foods. The role of multitarget preservation. Food Sci. Technol. Int. 1998, 4, 353-361. [CrossRef]

31. Xiao, J. Dietary flavonoid aglycones and their glycosides: Which show better biological significance? Crit. Rev. Food Sci. Nutr. 2017, 57, 1874-1905. [CrossRef]

32. Joubert, E.; Winterton, P.; Britz, T.J.; Ferreira, D. Superoxide anion and $\alpha, \alpha$-diphenyl- $\beta$-picrylhydrazyl radical scavenging capacity of rooibos (Aspalathus linearis) aqueous extracts, crude phenolic fractions, tannin and flavonoids. Food Res. Int. 2004, 37, 133-138. [CrossRef]

33. Darmanyan, A.P.; Gregory, D.D.; Guo, Y.; Jenks, W.S.; Burel, L.; Eloy, D.; Jardon, P. Quenching of singlet oxygen by oxygen- and sulfur-centered radicals: Evidence for energy transfer to peroxyl radicals in solution. J. Am. Chem. Soc. 1998, 120, 396-403. [CrossRef]

34. Kancheva, V.D. Phenolic antioxidants-Radical-scavenging and chain-breaking activity: A comparative study. Eur. J. Lipid Sci. Technol. 2009, 111, 1072-1089. [CrossRef] 
35. Heim, K.E.; Tagliaferro, A.R.; Bobilya, D.J. Flavonoid antioxidants: Chemistry, metabolism and structure-activity relationships. J. Nutr. Biochem. 2002, 13, 572-584. [CrossRef]

36. Wu, X.; Liu, Y.; Huo, T.; Chen, Z.; Liu, Y.; Di, D.; Guo, M.; Zhao, L. Multiple interactions on macroporous adsorption resins modified with ionic liquid. Colloids Surf. A Physicochem. Eng. Asp. 2015, 487, 35-41. [CrossRef]

37. Qiu, H.; Mallik, A.K.; Takafuji, M.; Liu, X.; Jiang, S.; Ihara, H. A new imidazolium-embedded C 18 stationary phase with enhanced performance in reversed-phase liquid chromatography. Anal. Chim. Acta 2012, 738, 95-101. [CrossRef] [PubMed]

38. Zheng, W.; Wang, Y.; Yang, L.; Li, X.; Zhou, L.; Li, Y. Novel adsorbent of polymeric complex derived from chaleting resin with $\mathrm{Cu}(\mathrm{II})$ and its removal properties for cyanide in aqueous solution. Colloids Surf. A Physicochem. Eng. Asp. 2014, 455, 136-146. [CrossRef]

39. Formagio, A.; Volobuff, C.; Santiago, M.; Cardoso, C.; Vieira, M.; Valdevina Pereira, Z. Evaluation of Antioxidant Activity, Total Flavonoids, Tannins and Phenolic Compounds in Psychotria Leaf Extracts. Antioxidants 2014, 3, 745-757. [CrossRef]

40. Lee, S.Y.; Mediani, A.; Maulidiani, M.; Khatib, A.; Ismail, I.S.; Zawawi, N.; Abas, F. Comparison of partial least squares and random forests for evaluating relationship between phenolics and bioactivities of Neptunia oleracea. J. Sci. Food Agric. 2018, 98, 240-252. [CrossRef]

41. Abdul-Hamid, N.A.; Mustaffer, N.H.; Maulidiani, M.; Mediani, A.; Ismail, I.S.; Tham, C.L.; Shadid, K.; Abas, F. Quality evaluation of the physical properties, phytochemicals, biological activities and proximate analysis of nine Saudi date palm fruit varieties. J. Saudi Soc. Agric. Sci. 2018, in press. [CrossRef]

Sample Availability: Samples of the compounds are available from the authors.

(C) 2020 by the authors. Licensee MDPI, Basel, Switzerland. This article is an open access article distributed under the terms and conditions of the Creative Commons Attribution (CC BY) license (http://creativecommons.org/licenses/by/4.0/). 